\title{
Overview of Commercially Available CEOS Hexapole-type Aberration Correctors
}

\author{
Heiko Müller, Stephan Uhlemann, Peter Hartel, Joachim Zach, and Max Haider \\ Corrected Electron Optical Systems GmbH, Englerstr. 28, D-69126 Heidelberg, Germany
}

\begin{abstract}
Aberration correctors have become essential equipment for high-resolution imaging and spectroscopy in STEM and CTEM. This is impressively documented by the large and still rapidly growing number of hexapole-type imaging and probe correctors installed all over the world. The optical design of the hexapole Cs-correctors in essence is based on the theoretical studies of Rose [1, 2]. It has been put into practice by Haider et al. during 1992-1997 [3, 4] and consists of a hexapole doublet and two transferlens systems. This design provided the basis for the CEOS imaging correctors (CETCOR) which are available for a variety of commercial TEM instruments. Subsequently, a similar design could be used to correct for the spherical aberration of the probe-forming system in a STEM, as well. Nowadays, it is not uncommon to have a double-corrected instrument with a probe corrector above and an imaging corrector below the objective lens.
\end{abstract}

The probe Cs-corrector (CESCOR) enables STEM resolution far below 1 Ångstrøm and allows for an increased aperture angle and, hence, much higher probe currents and improved signal-to-noise ratio. Additionally, the beam tilt can be adjusted without disturbing effects due to tilt-induced axial coma. The scan-coma can be eliminated, since the scan is performed between the corrector and the objective lens. Looking at the number of installations, we see a large demand for probe correctors due to the striking benefits of Cs-corrected STEM for analytical work at atomic resolution. Some vendors already have added probe Cs-correctors as obligatory components to their high-resolution (S)TEM instruments. To further improve the STEM performance the original design of the hexapole-type probe corrector has been enhanced $(D-C O R)$, firstly by correcting for the fifth-order spherical aberration and secondly by eliminating the six-fold astigmatism $[4,5]$. Also alignment methods to compensate for all parasitic $4^{\text {th }}$ order aberrations have been implemented. Due to these measures the maximum usable aperture angle is not limited by residual intrinsic aberrations anymore - not even for an instrument equipped with coldfield emission gun.

Recently, we observed that the request for imaging correctors is catching up. For CTEM imaging the Cs-corrector allows for a point resolution equal to the information limit and the delocalization is reduced from several nanometers down to the size of an atom. Linear phase contrast can be adjusted by optimally chosen values for defocus and spherical aberration. Also in CTEM the imaging corrector allows to tilt the beam without disturbing effects due to tilt-induced aberrations and the lateral incoherence due to the finite brightness of the electron source does not impact the information limit. Coma-free alignment becomes more simple than in an uncorrected instrument and non-parallel illumination does not cause strong non-isoplanatism anymore. Since the variation of the optical quality across the field of view became more and more a critical factor, in 2006 we proposed an entirely new imaging-corrector design based on a hexapole triplet. It has been realized successfully in 2010 [4, 6]. The novel hexapoletype corrector $(B-C O R)$ enables fully aplanatic imaging and 4th-and 5th-order axial correction. The linear off-axial aberrations of 1 st, 2 nd and 3rd order as well as the six-fold astigmatism are corrected. With the $D-C O R$ and $B-C O R$ design for the advanced hexapole-type probe and imaging corrector, respectively, the optical technology for high-resolution imaging has achieved a mature state. Future developments and improvements will probably concentrate on dedicated Cs-corrected 
instruments for new fields of applications like Lorentz, low-voltage, in-situ, ultra-high voltage, or cryo microscopy and time-resolved and spectroscopic imaging. In some of these fields - beside hexapole-type Cs-correctors -also quadrupole-octupole $\mathrm{Cc} / \mathrm{Cs}$-correctors will gain more importance, since this alternative optical design allows for the simultaneous compensation and tuning of the geometrical as well as the chromatic aberrations.

\section{References:}

[1] H. Rose, Nucl. Instr. Meth. A 187 (1981) 187-199.

[2] H. Rose, Optik 85 (1990) 19-24.

[3] M. Haider, et al., Nature 392 (1998) 768--769.

[4] M. Haider, H. Müller, and S. Uhlemann, Adv. Imag. Electr. Phys. 153 (2008) 43-118.

[5] H. Müller, et al., Microsc. Microanal. 12 (2006) 442-455.

[6] H. Müller, et al., Nucl. Instr. Meth. A 645 (2011) 20-27.

\begin{tabular}{|c|c|c|c|}
\hline Corrector Design & Properties and capabilities & $\begin{array}{l}\text { Residual } \\
\text { aberrations }\end{array}$ & $\begin{array}{lll}\begin{array}{l}\text { Available for } \\
\text { platforms }\end{array} & & \\
\end{array}$ \\
\hline $\begin{array}{lr}\text { CETCOR } & \\
\text { imaging } & \text { corrector } \\
\text { hexapole } & \text { doublet } \\
\text { (since 2001) } & \end{array}$ & $\begin{array}{l}\text { - 3rd-order axial auto-alignment } \\
\text { - C3 user-adjustable } \\
\text { - semi-aplanatic by design }\end{array}$ & $\begin{array}{l}\mathrm{C} 5>0 \\
|\mathrm{~A} 5|>0\end{array}$ & $\begin{array}{llr}\text { FEI Tecnai } & \text { F20 } & \text { JEOL } \\
\text { JEM2100F } & \text { Zeiss } & \text { Libra } \\
200 & & \\
\text { FEI Titan 80-300 } & \\
\text { JEOL ARM 200 } & \end{array}$ \\
\hline $\begin{array}{lr}\text { CESCOR } & \\
\text { probe } & \text { corrector } \\
\text { hexapole } & \text { doublet } \\
\text { (since 2003) } & \end{array}$ & $\begin{array}{l}\text { - 3rd-order axial auto-alignment } \\
\text { - C5-free by design }\end{array}$ & $\begin{array}{l}\mathrm{C} 5 \approx 0 \\
|\mathrm{~A} 5|>0\end{array}$ & $\begin{array}{l}\text { JEOL JEM2100F } \\
\text { Hitachi HD-2700 } \\
\text { Zeiss Libra } 200 \\
\text { FEI Titan } 80-300 \\
\text { JEOL ARM } 200\end{array}$ \\
\hline $\begin{array}{l}\text { D-COR } \\
\text { probe corrector } \\
\text { hexapole doublet } \\
\text { (since 2007) }\end{array}$ & $\begin{array}{l}\text { - 4th-order axial auto-alignment } \\
\text { - C5-free by design } \\
\text { - A5-minimized by design }\end{array}$ & $\begin{array}{l}\mathrm{C} 5 \approx 0 \\
\mathrm{~A} 5 \approx 0\end{array}$ & $\begin{array}{l}\text { FEI Titan 80-300 } \\
\text { JEOL ARM } 200 \\
\text { and others on request... }\end{array}$ \\
\hline $\begin{array}{l}\text { B-COR } \\
\text { imaging corrector } \\
\text { hexapole triplett } \\
\text { (since 2010) }\end{array}$ & $\begin{array}{l}\text { - 4th-order axial auto-alignment } \\
\text { - C3 user-adjustable } \\
\text { - A5-free by design } \\
\text { - fully aplanatic by design } \\
\text { - 3rd-order off-axial auto-alignment }\end{array}$ & $\begin{array}{l}\mathrm{C} 5>0 \\
\mathrm{~A} 5 \approx 0\end{array}$ & $\begin{array}{l}\text { Hitachi HF-3300S } \\
\text { and others on request... }\end{array}$ \\
\hline
\end{tabular}

Table 1. Overview of the commercially available CEOS hexapole-type aberration correctors grouped by the principle of the optical design with capabilities and limitations. Performance and magnitude of residual aberrations (C5: fifth-order spherical aberration, A5: fifth-order, six-fold astigmatism) may vary depending on platform and chosen objective-lens pole piece and electron source. 